\title{
MODERATING ROLE OF PERCEIVED ORGANIZATIONAL SUPPORT BETWEEN ORGANIZATIONAL CITIZENSHIP BEHAVIOR AND ORGANIZATIONAL PERFORMANCE AMONG INDUSTRIAL EMPLOYEES
}

\author{
Andleeb Akhtar ${ }^{1 *}$, Sadaf Ahsan ${ }^{2}$, Syeda Naila Andleeb ${ }^{3}$, Saira Bano ${ }^{4}$, Rimsha Kainat ${ }^{5}$ \\ ${ }^{1 *}$ Lecturer Psychology, The University of Haripur, Haripur, Pakistan \& Phd Scholar, Department of Psychology, \\ Foundation University Islamabad, Pakistan; ${ }^{2}$ Associate Professor, Department of Psychology, Foundation University \\ Islamabad, Pakistan; ${ }^{3}$ Department of Psychology, Foundation University, Islamabad, Pakistan; ${ }^{4}$ Lecturer Psychology, \\ The University of Haripur, Haripur, Pakistan; ${ }^{5}$ Department of Psychology, The University of Haripur, Haripur, Pakistan. \\ Email: ${ }^{1 *}$ andleebmalik81@yahoo.com, ${ }^{2}$ sdfmuneer@yahoo.com, ${ }^{3}$ andleebsyeda@gmail.com, \\ ${ }^{4}$ sara.sheraz24@gmail.com, ${ }^{5}$ rimsha.psy.msc1@gmail.com
}

Article History: Received on $15^{\text {th }}$ April 2021, Revised on $27^{\text {th }}$ April 2021, Published on $1^{\text {st }}$ May 2021

\begin{abstract}
Purpose of the study: The present research paper investigated the moderating role of perceived organizational support on the relationship between organizational citizenship behavior and organizational performance.

Methodology: The sample consisted of 205 employees from different organizations in Hattar Industrial State and Haripur, Pakistan. The Perceived Organizational Support (Eisenberger et al., 1986), the Organizational Citizenship Behavior (Podsakoff et al., 2009), and the Organizational Performance (Kuo, 2011) scales were used to attain the desired results. A purposive sampling technique was used with a cross-sectional survey research design. The employees from Hattar Industrial State were taken as the target sample. The statistical analysis was done using SPSS 21. The alpha reliability, Pearson correlation, t-test, ANOVA, linear and multiple regressions were calculated along with demographic analysis to meet the objectives of the study.

Main Findings: Results indicated a highly significant positive correlation between OCB, POS, and OP. The results also showed that OCB and POS are significant predictors of OP. The gender differences are non-significant. The differences are significant between groups at upper, middle, lower, senior, and other management levels. The results showed significant differences between age groups with late age adults (46-60 years age) having high mean scores in organizational citizenship behavior and organizational performance. Among the demographic variables: age, average salary, and organizational size are significantly impacting organizational citizenship behavior, perceived organizational support, and organizational performance. The results indicated that perceived organizational support moderated the relation between organizational citizenship behavior and organizational performance significantly.
\end{abstract}

Applications of the study: The study findings are important for organizations, officials, and managers to further develop work attitudes and work behaviors and enhance their performance and productivity.

Novelty: Very few researchers have studied the employees in industrial settings. People spend a major part of their life in the workplace. Their work is affected by several organizational factors as well as their subjective factors. The impact of demographic variables has also been studied. Thus, this study provided insights into factors that affect employee performance.

Keywords: Age, Gender, Organizational Citizenship Behavior (OCB), Perceived Organizational Support, Organizational Performance, Hattar Industrial State, Management levels.

\section{INTRODUCTION}

In today's modern and developing era every organization strives for competitiveness by having and providing one of the best human resources to its employees (Singh \& Singh, 2013). Organizations cannot cultivate the effectiveness of collective wisdom devoid of the voluntary willingness of individuals to cooperate and collaborate which is very important. The market scenario has been rapidly changed with global economic pressures, technological advances, and changing customer's needs and wants. It has placed enhanced levels of competitive pressures and survival challenges to the enterprises by the increased complexity of environmental changes and enterprise performance expectations. Enterprises are becoming more reactive, fast, innovative, and competitive due to globalization. They need to know of appropriate workplace OCBs and to plan and deploy these OCBs effectively (Beauregard, 2012). Employees who have high occupational efficacy (OE) show more voluntary behaviors in helping co-workers with work-related problems as they proactively plan and organize their activities of the workday and accommodate them (Reizer \& Hetsroni, 2015).

The effective working of any institution is usually promoted by employee citizenship behaviors without affecting human resource productivity. It makes OCB an area of recent interest in the literature related to employee behaviors, however, the scarcity of literature on organizational silence and OCB is astonishing. Acaray and Akturan (2015) explained the true employee as one who demonstrates OCB and higher contextual performance (Paille, 2011). There are several benefits of OCB in organizational settings such as enhanced productivity, enhanced service quality, increased customer value, and 
decreased levels of customer complaints. Most of the past literature has been mainly focusing on determinants of OCB. Lam et al. (2016) researched that OCBs increase employees' energy, enhancing employee s' capacities and ultimately better well-being is achieved. OCB forecasts performance (e.g., Lam et al., 2016; Park, 2018; Germeys et al., 2019). Furthermore, self-efficacy of the job proved a core precursor of OCB among customer-service employees and facilitate OCB. Occupational Efficacy (OE) predicts OCB (Reizer \& Hetsroni, 2015). It impacts employees' performance. OCB is thus a good antecedent of creativity, efficiency, and general performance other than the quality performance. These conclusions provide a precise and deep understanding of the impacts of OCB in facets of performance more than reported in the literature (Choi, 2009; Germeys et al., 2019; Lam et al., 2016; Park, 2018).

Perceived organizational support (POS) is the global confidence of staff towards the organization. POS increases employees' felt obligation to help the organization in achieving its goals, their affective commitment, and their expectation of reward for improved performance. Social effects of POS contain augmented in-role and extra-role functioning and decreased nonappearance and staff renewal rate. The theory of organizational support (OST), explains that employees of the organization develop a generalized perception of the extent to which the organization cares for their well-being and values their contributions towards goals. The POS is attached with risky behaviors of employees and their immediate supervisors based on inner confidence that organizational management will take the failure as a process of innovation and effort. The human resources who are confident about the perception of support by the organization about care and well-being will more likely to go the extra mile to achieve organizational objectives. Studies confirm the nature of the association between OCB and perceived organizational support. Duffy and Lilly (2013) established that the average demand for success and influence impacted the relationship between these two constructs. Psychological empowerment and perceived support impacted positively on citizenship behaviors (Chiang \& Hsieh, 2012). Jain et al. (2013) confirmed a direct significant correlation between OCB and POS. POS is directly and significantly correlated to OCB (Muhammad, 2014; Jebeli and Etebarian (2015) Singh and Singh (2013) found mediating role of personality between POS and OCB. Sidra et al. (2016) confirmed the moderation of psychological capital between these two variables. POS reduces counterproductive work behaviors and employee emotional exhaustion (Kurtessis et al., 2017), which increases 2\% of personnel costs (Taris \& Schreurs, 2009).

In literature organizational performance is considered to cater for three main areas such as performance of the satisfaction delivered by product or service, financial achievements of the organization, and ROI gain of shareholders of the organization. On the other hand, is a term called organizational effectiveness which deals with the efficiency of operational excellence. Some specific approaches provide enhanced awareness about matters related to efficiency and effectiveness in organizations, one such approach is the balance scorecard approach (Alexandru, 2012). Profit per employee is most widely used and a deemed crucial marker of organizational performance (Datta et al., 2005; Shaw et al., 2013).

The literature review (Cullen et al., 2014; Eisenberger \& Stinghamber, 2014; Gavino et al., 2012) concluded that POS enhances employee performance and enhances the efficiency of the organization. Highly shared POS within the organization, payback the organization's lower level staff. Organizational support theory states that employees' high POS motivates them in helping the organization to reach its objectives. POS leads to increased affective organizational commitment (e.g., Allen \& Shanock, 2013). Yaakobi and Weisberg (2020) confirmed Occupational Efficacy (OE) as an antecedent of OCB in determining performance. OCB predicts employee performance positively in addition to consequences of the position of their managers' tenure and Collective Efficacys' (CE). Besides, employees' and managers' CEs moderated the relation of OCB with performance: thus enhancing efficiency, creativity, and general performance. It leads to higher performance in organizational settings.

Very few researchers have studied the employees in industrial settings. People spend a major part of their life in the workplace. Their work is affected by several organizational factors as well as their subjective factors. As cited in literature that OCB and POS enhance organizational performance, the present research has studied them together. The perception of the support from the organization may enhance the OCBs towards performance. Therefore, the present study is aimed to find out the relationships between organizational citizenship behavior, perceived organizational support, and organizational performance. The moderating role of POS between OCB and organizational performance and industrial employees of different organizations as target samples has been focused.

\section{Research Highlights}

- Study of relationships between OCB, POS, and OP.

- Using refined research models: OCB and POS.

- OCB and POS predict OP among industrial employees significantly.

- Differences in demographic characteristics in OCB, POS, and OP are significant.

- Impact of demographic variables on OCB, POS, and OP significant.

- POS moderated the relation between OCB and OP significantly. 


\section{Theoretical Framework}

The cross-sectional survey research design and purposive sampling technique were used.

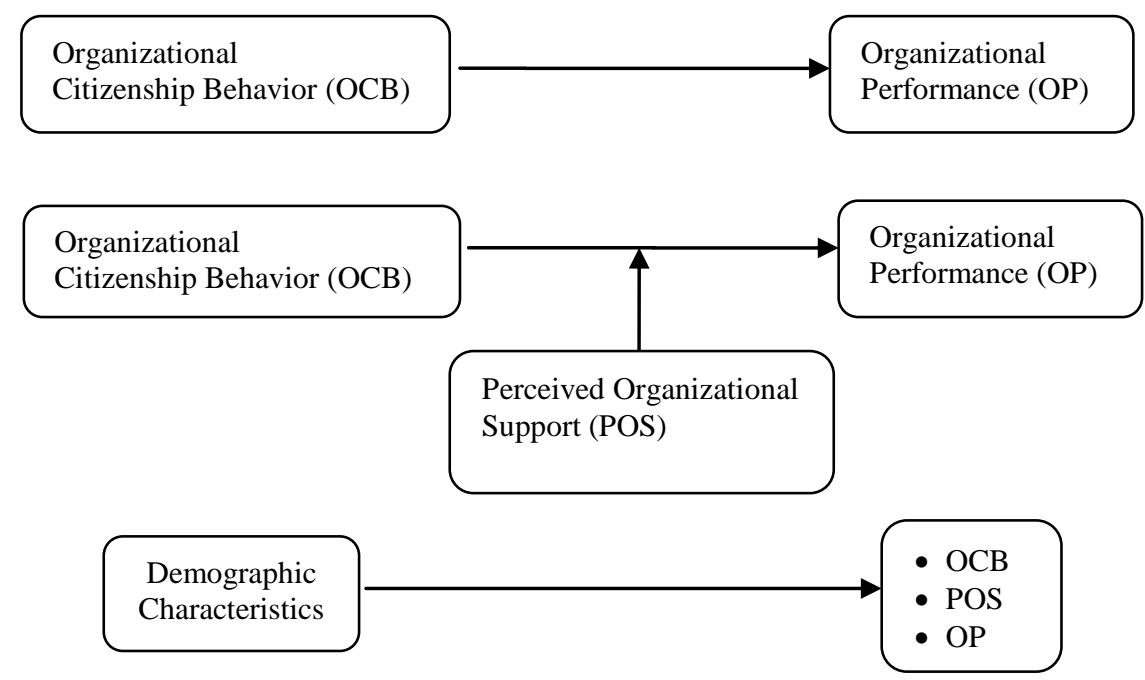

Source: Author Conceptualization

\section{Objectives}

The objectives of the research included investigations:

1 To establish the psychometric properties of the scales culturally.

2 To study industrial employees.

3 To study the relationship between Organizational Citizenship Behavior, Perceived Organizational Support, and Organizational Performance.

4 To study the impact of demographic variables and between-group differences.

5 To examine the moderating role of POS between OCB and OP.

\section{Hypotheses}

The hypotheses of the research included investigations

H1: There will be a positive relationship between Organizational Citizenship Behavior and Organizational Performance and Perceived Organizational Support.

H2: Perceived Organizational Support and Organizational Citizenship Behavior will positively predict Organizational Performance.

H3: Male employees will score higher on Perceived Organizational Support, Organizational Citizenship Behavior, and Organizational Performance than female employees.

H4: There will be significant group differences among different management levels Perceived Organizational Support, Organizational Citizenship Behavior, and Organizational Performance.

H5: There will be a significant difference among age groups in Perceived Organizational Support, Organizational Citizenship Behavior, and Organizational Performance.

H6: Demographic characteristics will impact Perceived Organizational Support, Organizational Citizenship Behavior, and Organizational Performance.

H7: Perceived Organizational Support will moderate the relationship between Organizational Citizenship Behavior and Organizational Performance.

\section{Method and Sample}

The research was conducted with a cross-sectional survey research design. The purposive non-probability sampling technique was used. The sample consisted of subjects from different organizations in Hattar Industrial State and Haripur Pakistan (Ecopak, Pine Match, WAPDA, EBM). The demographic variables of the sample included management levels, age, gender, and education. The management levels included top management, middle and lower management. The job experience of the employees ranged from 2 to 15 years. The age of the subjects ranged from 18 years to 60 years. The study requirements also included that the sample must be literate. The participants were approached and briefed about 
the purpose of the study. They were requested to fill the questionnaires. Perceived Organizational Support: the survey of Perceived Organizational Support (SPOS) shorter 8-item version scale (Eisenberger et al. 1986) was used. Items are rated on seven point-rating scales (Likert scale) that range from 0 (strongly disagree) to 6 (strongly agree). It's a shorter 8 -item version scale with items number 1,3,7,9,17,21,23 and 27 from the original scale. Items 3,7,17,23 are reversely scored items and the minimum score is 8 and the highest score is 40 . The reliability of the scale is .84 . Organizational citizenship behaviour (OCB): it is measured by using the scale of Podsakoff et al. (2009). The brief version of this scale was tested and modified by Kumar and Shah (2015). It has 15 items. The scale measure five traits of Organizational Citizenship Behavior (OCB) that are conscientiousness, sportsmanship, civic virtue, courtesy, and altruism. Items number 1,2, 3 measure altruism. The items number 4, 5, 6 measure courtesy. Items 7,8,9 measure civic virtue. Items number 10, 11, 12 measure sportsmanship behavior. Items number 13,14,15 measure conscientiousness. The items are given on 7 point-rating scale (Likert scale) that ranges from strongly disagree (1) to strongly agree (7). Items $10,11,12$ are the reverse items and scored reversely. The score ranges from a minimum score of 15 to a maximum score of 105. The reliability of the scale determined is 0.71 Organizational Performance: it is measured by the questions regarding organizational performance on a 5-point Likert scale (' 1 ' strongly disagree to ' 5 ' strongly agree) using 6 items from the scale developed by Kuo (2011). The score ranges between 6 to 30. The established reliability of the scale is .81 . The subjects were instructed and assured of confidentiality before the administration of the booklet of questionnaires. The questionnaires were collected back and thanked for their cooperation. SPSS 21 was used for data analyses. The data was arranged and analyzed statistically. For hypothesis testing. Alpha reliability, Pearson correlation, regression, t-test, ANOVA, and moderation analysis has been carried.

\section{FINDINGS}

Table 1: Frequency and percentages of groups reporting demographic information among industrial employees ( $\mathrm{n}=205)$

\begin{tabular}{llll}
\hline Demographic Variables & Groups & F & \% \\
\hline Gender & Male & 195 & 95.1 \\
\hline Age & Female & 10 & 4.9 \\
\hline & 20 - 30 years & 89 & 43.4 \\
\hline & 31 - 45 years & 76 & 37.1 \\
\hline Management levels & 46 - 65 years and above & 39 & 19.0 \\
\hline & Lower Management & 96 & 46.8 \\
\hline & Middle Management & 67 & 32.7 \\
\hline & Senior Management & 27 & 13.2 \\
\hline & Other & 15 & 7.3 \\
\hline
\end{tabular}

The demographic variables were measured as categorical variables which include gender, age, and management level. Table 1 is analyzed, the participants were $87 \%$ males ( 87 persons) and $13 \%$ women (13 persons). When the age levels of the participants were considered 20-30 years the aged group was 51\% (51 people), 31-45 years the aged group was $45 \%$ (45 people), 46-60 years and above aged group was $4 \%$ (4 people). When the management levels of the participants were analyzed, lower management level consisted of 42\% (42 people), middle management level consisted of $39 \%$ (39 people), senior management level consisted of $11 \%$ (11 people) and 'other' included internees/daily wage employees that were $8 \%$ ( 8 people).

Table 2: Psychometric properties of scales and Pearson Correlation among OCB, POS and OP of Industrial Employees $(\mathrm{n}=205)$

\begin{tabular}{llllllllll}
\hline Variables & No of items & \multicolumn{2}{l}{ Range } & Mean & SD & $\boldsymbol{\alpha}$ & I & II & III \\
\hline 1. OCB & 15 & 31.0 & 105.0 & 72.75 & 14.81 & .86 & -- & $.495^{* * *}$ & $.566^{* * *}$ \\
\hline 2. POS & 8 & 14.0 & 40.00 & 26.80 & 5.13 & .65 & -- & -- & $.627 * * *$ \\
\hline 3. OP & 6 & 7.0 & 30.00 & 20.50 & 5.20 & .80 & -- & -- & -- \\
\hline
\end{tabular}

$\mathrm{p}=.000$, Note: $\mathrm{OCB}=$ Organizational Citizenship Behavior, OP=Organizational Performance, POS=Perceived Organizational Support

Table 2 shows the psychometric properties of scales. The reliability analysis indicates that the alpha reliability of OCB, POS, and OP are $.86, .65$, and .80 respectively which indicate satisfactory internal consistency. Results also show the Pearson correlation between OCB, POS, and OP are ranging from $.539^{* * *}$ to $.627^{* *}$. The results confirmed a highly significant strong positive correlation between OCB, POS, and OP with $\mathrm{p}<0.001$.

Table 3: Multiple Regression Coefficients predicting OP from OCB and POS

\begin{tabular}{llllclll}
\hline & $\mathbf{B}$ & $\mathbf{S E}$ & $\boldsymbol{\beta}$ & $\mathbf{t}$ & $\mathbf{p}$ & \multicolumn{2}{c}{ 95\% C I [LL- UL] } \\
\hline Constant & -.636 & 1.571 & & -.405 & .686 & -3.733 & 2.461 \\
\hline OCB & .119 & .021 & .339 & 5.807 & .000 & .079 & .160 \\
\hline
\end{tabular}




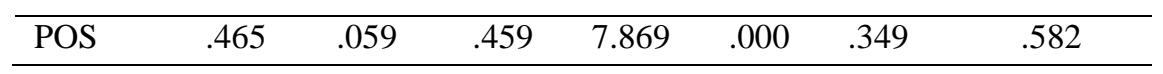

$\mathrm{R}=. .693, \mathrm{R}^{2}=.480$, Adjusted $\mathrm{R}^{2}=.475$

The multiple regression analysis showed that OCB and POS significantly predict OP. The predictor variables OCB $(\beta=$ .339) and POS $(\beta=.459)$ have significant positive effect on outcome variable with level of significant $\mathrm{p}=.000$. The adjusted $\mathrm{R}^{2}$ of .480 indicated OCB and POS cause high significant variation; $48 \%$ in OP among industrial employees with $\mathrm{F}(\mathrm{df}=2,202)=93.306, \mathrm{p}=.000$

Table 4: $t$-test for Gender Differences on OCB, POS, and OP among Industrial Employees $(n=205)$

\begin{tabular}{|c|c|c|c|c|c|c|}
\hline \multirow[t]{2}{*}{ Variables } & \multicolumn{2}{|c|}{ Male(N=195) } & \multicolumn{2}{|c|}{ Female(N=10) } & \multirow[b]{2}{*}{$\mathbf{t}$} & \multirow[b]{2}{*}{$\mathbf{p}$} \\
\hline & $\mathbf{M}$ & SD & $\mathbf{M}$ & SD & & \\
\hline OCB & 72.83 & 14.67 & 71.10 & 18.21 & .361 & .719 \\
\hline POS & 26.89 & 5.15 & 25.20 & 4.82 & 1.016 & .311 \\
\hline $\mathrm{OP}$ & 20.49 & 5.21 & 20.70 & 5.22 & -.123 & .902 \\
\hline
\end{tabular}

df $=201$ Note, OCB=Organizational Citizenship Behavior, OP=Organizational Performance, POS=Perceived Organizational Support

Table 4 shows that the gender differences are non-significant in OCB, POS, and OP.

Table 5: Mean, standard deviation and one-way Analysis of Variance (ANOVA) OCB, POS, and OP among management levels of industrial employees $(n=205)$

\begin{tabular}{lllllllllll}
\hline Variables & \multicolumn{2}{l}{ Lower Management } & \multicolumn{2}{l}{ Middle management } & \multicolumn{2}{l}{ Senior management } & Other & \multirow{2}{*}{$\mathbf{F}(\mathbf{3 , 2 0 1})$} & $\boldsymbol{\eta}^{2}$ \\
\cline { 2 - 13 } & M & S.D & M & S.D & M & S.D & M & S.D & & \\
\hline OCB & 71.9 & 17.48 & 75.67 & 12.08 & 74.22 & 9.79 & 62.46 & 9.67 & $3.60^{* *}$ & .05 \\
\hline POS & 27.56 & 6.10 & 26.08 & 26.08 & 27.74 & 4.17 & 23.53 & 2.92 & $3.58^{* *}$ & .05 \\
\hline OP & 20.60 & 20.60 & 20.52 & 5.30 & 21.70 & 3.50 & 17.60 & 2.82 & 2.08 & .03 \\
\hline
\end{tabular}

Note: $\mathrm{OCB}=$ Organizational Citizenship Behavior, OP=Organizational Performance, POS=Perceived Organizational Support

To study the group differences between management levels in organizational citizenship behavior, perceived organizational support, and organizational performance one-way ANOVA was carried out. It compared the management level groups by comparing their mean values. The results also show that the employees' scores have significant differences, by management levels. The differences are significant between groups at upper, middle, lower, senior, and other management levels. The $\eta^{2}$ for organizational citizenship behavior $=.014$ and for Perceived organizational support $=.015$ and Organizational performance $=.104$ revealed that the effect size between group means is of moderate effect. The differences are significant.

Table 6: Mean, Standard Deviation and one-way Analysis of Variance (ANOVA) OCB, POS, and OP among Age Groups of Industrial Employees $(\mathrm{n}=205)$

\begin{tabular}{|c|c|c|c|c|c|c|c|c|}
\hline \multirow[b]{2}{*}{ Variables } & \multicolumn{2}{|c|}{$15-30$ years aged } & \multicolumn{2}{|c|}{ 31-45 years aged } & \multicolumn{2}{|c|}{ 46-60 years aged } & \multirow[t]{2}{*}{$F(1,203)$} & \multirow[t]{2}{*}{$\eta^{2}$} \\
\hline & $\mathrm{M}$ & S.D & $\mathrm{M}$ & S.D & $\mathrm{M}$ & S.D & & \\
\hline $\mathrm{OCB}$ & 69.61 & 14.82 & 74.4 & 15.81 & 76.3 & 11.41 & $2.69 *$ & .03 \\
\hline POS & 25.86 & 5.32 & 27.6 & 5.23 & 27.1 & 4.02 & $2.82 *$ & .04 \\
\hline $\mathrm{OP}$ & 19.25 & 5.47 & 21.4 & 5.02 & 21.46 & 4.42 & $3.12 *$ & .04 \\
\hline
\end{tabular}

Note: $\mathrm{OCB}=$ Organizational Citizenship Behavior, OP=Organizational Performance, POS=Perceived Organizational Support

The results in the table show that the employees have significant differences in Organizational citizenship behavior, Perceived organizational support, and Organizational performance between different age groups. The age group's differences are significant. The $\eta^{2}$ for $\mathrm{OCB}=.03$ and for POS $=.04$ and $\mathrm{OP}=.04$.

Table 7: Regression coefficients of demographic characteristics on OCB, POS, and OP among industrial employees ( $\mathrm{n}=$ 205)

\begin{tabular}{llllllll}
\hline Predictor Variables & $\mathbf{B}$ & SE & $\boldsymbol{\beta}$ & $\mathbf{t}$ & $\mathbf{p}$ & \multicolumn{3}{c}{$\begin{array}{l}\text { 95\% C I } \\
{[\mathbf{L L}-\mathbf{U P}]}\end{array}$} \\
\hline & \multicolumn{7}{c}{ Dependent Variable: OCB } \\
\hline (Constant) & 63.765 & 6.753 & & 9.442 & .000 & 50.447 & 77.082 \\
\hline Gender & -2.018 & 4.703 & -.029 & -.429 & .668 & -11.292 & 7.257 \\
\hline Age & 4.345 & 1.338 & .225 & $3.246^{* *}$ & .001 & 1.705 & 6.984 \\
\hline
\end{tabular}




\begin{tabular}{llllllll}
\hline Management Level & .234 & 1.213 & .015 & .193 & .847 & -2.158 & 2.626 \\
\hline Average Salary & -3.617 & 1.570 & -.194 & $-2.304^{*}$ & .022 & -6.713 & -.521 \\
\hline Organizational Size & 4.364 & 1.437 & .229 & $3.036^{* *}$ & .003 & 1.529 & 7.198 \\
\hline \multicolumn{7}{c}{$\mathrm{R}^{2}=.089, \Delta \mathrm{R}^{2}=.066, \mathrm{~F}(5,198)=3.89 * *$} \\
\hline \multicolumn{7}{c}{ Dependent Variable: POS } \\
\hline Constant) & 27.70 & 2.337 & \multicolumn{7}{c}{11.85} & .000 & 23.10 & 32.31 \\
\hline Gender & -2.126 & 1.628 & -.089 & -1.30 & .193 & -5.33 & 1.08 \\
\hline Age & 1.223 & .463 & .183 & $2.64^{* *}$ & .009 & .310 & 2.13 \\
\hline Management Level & -.278 & .420 & -.050 & -.662 & .509 & -1.106 & .550 \\
\hline Average Salary & -1.592 & .543 & -.246 & $-2.93^{*} *$ & .004 & -2.664 & -.520 \\
\hline Organizational Size & 1.157 & .497 & .175 & $2.32^{*}$ & .021 & .176 & 2.13 \\
\hline \multicolumn{7}{c}{$\mathrm{R}^{2}=.09, \Delta \mathrm{R}^{2}=.071, \mathrm{~F}(5,198)=4.08^{* * *}$} \\
\hline Dependent Variable: OP \\
\hline Constant) & 18.805 & 2.416 & 7.784 & .000 & 14.04 & 23.56 \\
\hline Gender & -.163 & 1.682 & -.007 & -.097 & .923 & -3.480 & 3.155 \\
\hline Age & 1.451 & .479 & .214 & $3.03 * *$ & .003 & .507 & 2.395 \\
\hline Management Level & .031 & .434 & .005 & .071 & .944 & -.825 & .886 \\
\hline Average Salary & -1.055 & .562 & -.161 & -1.87 & .062 & -2.163 & .053 \\
\hline Organizational Size & .515 & .514 & .077 & 1.00 & .318 & -.499 & 1.52 \\
\hline & $\mathrm{R}^{2}=.056, \Delta \mathrm{R}^{2}=.032, \mathrm{~F}(5,198)=2.35^{*}$ \\
\hline
\end{tabular}

Note: $\mathrm{OCB}=$ Organizational Citizenship Behavior, $\mathrm{OP}=$ Organizational Performance, POS=Perceived Organizational Support

For studying the impact of demographic characteristics on OCB, POS and OP multiple regressions were performed. The demographic included Gender, Age, Management Levels, Average Salary, and Organizational size. These demographics predict and impact OCB, POS and OP significantly with $\mathrm{F}(5,198)=3.89^{* *}, \mathrm{~F}(5,198)=4.08^{* * *}, \mathrm{~F}(5,198)=2.35^{*}$ respectively. For OCB and POS, of the other demographic variables age, average salary, and organizational size are impacting significantly. For OP, of the other demographic variables only age is significantly impacting. The adjusted $\mathrm{R}^{2}$ values for OCB, POS, and OP show that variances of $6.6 \%$ in OCB, $7.1 \%$ in POS, and 3.2\% in the OP are accounted for on the demographic variables. Thus, the demographic characteristics significantly impact the OCB, POS, and OP of employees, which is confirmed by the present study.

Table 8: POS Moderation analysis of POS between OCB and OP among Industrial Employees ( $\mathrm{n}=205)$

\begin{tabular}{lcccccc}
\hline \multicolumn{1}{c}{ Variables } & B & SE & t & $\mathbf{p}$ & \multicolumn{2}{c}{$\mathbf{9 5 \%}$ C I } \\
& & & & & \multicolumn{2}{c}{$[\mathbf{L L}-\mathbf{U P}]$} \\
\hline (Constant) & 20.714 & .287 & 72.035 & .000 & 20.1478 & 21.2819 \\
\hline OCB (IV) & .111 & .020 & 5.361 & .000 & .0706 & .1527 \\
\hline POS (Moderator) & .484 & .059 & 8.104 & .000 & .3666 & .6023 \\
\hline OCB x POS & -.005 & .003 & -1.789 & .05 & -.0119 & .0006 \\
(IV x Moderator) & & & & & & \\
\hline
\end{tabular}

Note: $\mathrm{R}^{2}=.48, \Delta \mathrm{R}^{2}=.008$, OCB=Organizational Citizenship Behavior, $\mathrm{OP}=$ Organizational Performance, POS=Perceived Organizational Support

To test the hypotheses that Perceived organizational support will moderate the impact of Organizational Citizenship Behavior and organizational performance. The values represent that there is moderation present as by a significant interaction effect, $\beta=-.0057,95 \%$ CI $[-.011,-.000], \mathrm{t}=-1.78, \mathrm{p}=.05$, indicating that the relationship between Organizational Citizenship Behavior and organizational performance is moderated by Perceived organizational support. The results show that $\mathrm{R}^{2}=.48$ and, $\Delta \mathrm{R}^{2}=.008$ with $\mathrm{F}(201)=3.20$ and $\mathrm{p}=.05$ is significant. POS moderated the impact of Organizational Citizenship Behavior in organizational performance by $0.8 \%$. The results indicated that Perceived organizational support moderated the relation between Organizational Citizenship Behavior and organizational performance significantly. The results supported the objectives of this study.

Table 9: Conditional effect of OCB in OP at different values of POS among industrial employees $(n=205)$

\begin{tabular}{ccccccc}
\hline POS & Effect of POS in OCB & SE & t & p & $\begin{array}{c}\text { 95\% C I } \\
{[\text { LL }- \text { UP] }}\end{array}$ \\
\hline$-4.809(-1 \mathrm{SD})$ & .138 & .023 & 5.98 & .000 & .093 & .184 \\
\hline$-.809(\mathrm{M})$ & .116 & .020 & 5.67 & .000 & .075 & .156 \\
\hline $5.19(+1 \mathrm{SD})$ & .082 & .029 & 2.83 & .005 & .025 & .139 \\
\hline
\end{tabular}


Note: OCB=Organizational Citizenship Behavior, OP=Organizational Performance, POS=Perceived Organizational Support

Table 9 displays the conditional effect of OCB in OP at different values (at 1 SD below mean, at mean and 1 SD above mean) of POS. The relationship between OCB and OP is substantial $(\beta=.138, p=.000)$ at 1 standard deviation was found to be beneath the average value of moderating variable. Reported further significantly high associations ( $\beta=.112$, $\mathrm{p}=.000)$ average digit value of moderating construct. At a $1 \mathrm{Sd}$ accounted value the very large $(\beta=.082)$ and highly significant $(\mathrm{p}=.005)$. The conditional effect of OCB in OP transitioned is significant below and above this threshold and becomes more significant above it. The interaction effect is further shown in Figure 1.

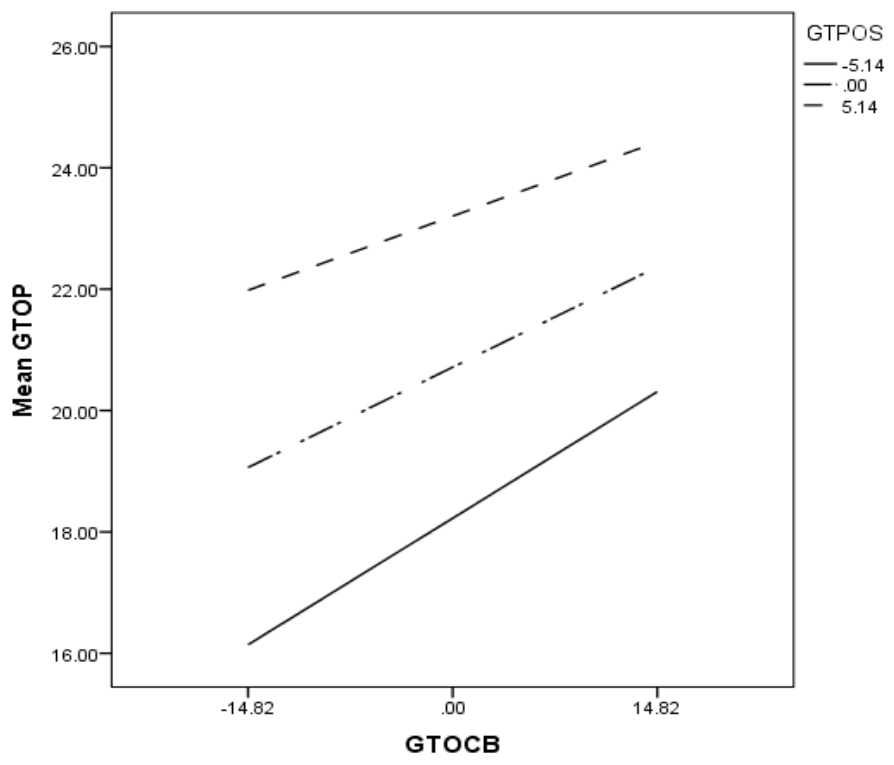

Figure 1: Moderating Role of POS between OCB and OP

Note: $\mathrm{GTOCB}=$ Organizational Citizenship Behavior. GTOP=Organizational Performance, GTPOS=Perceived Organizational Support

Figure 1 illustrated that POS plays a significant role as a moderator between Organizational Citizenship Behavior and organizational performance.

\section{DISCUSSION}

The results of this study are important in determining the relationships between organizational performance and organizational citizenship behavior with perceived organizational support as a moderator. The first and second hypothesis of the study is given in table 2 and 3. The results have confirmed that OCB and POS have a very positive highly significant correlation with organizational performance and they predict organizational performance significantly. The previous researches also show similar results (Eisenberger et al., 1986; Rhoades \& Eisenberger, 2002; Paille, 2011).

The third hypothesis about gender differences in OCB, POS, and OP was not supported. The gender differences are nonsignificant. Previous literature shows mixed results about the gender differences (Robbins and Judge, 2015).

The fourth hypothesis and table 5 showed significant differences among employees between different management levels in organizational citizenship behavior. Also, results of organizational performance have shown a significant difference between the management levels. The middle management level has scored high in both variables. Researchers generally assert that OCB is positive for organizations and is beneficial at different management levels. Managers believing in OCB create a cooperative environment for employees. OCB saves time for managers by directing employees in performing their duties and focusing on opportunities for improving organizational performance. The differences exist between employees at different levels of management on other variables as well (DiRenzo, Greenhaus, $\underline{\& \text { Weer, 2011). }}$.

The fifth hypothesis and table 6 results showed that there are significant differences among different age groups. The previous research also indicated consistent results with work perceptions, attitudes, and behaviors among different age groups age (e.g., Stamper \& Van Dyne, 2001).

Demographic characteristics have also been analyzed as predictors. Previous researches have also taken demographic characteristics as predictors and found different results (Sikorska-Simmons, 2005). The sixth hypothesis has been supported by the present research. 
And the seventh hypothesis explores the moderating role of POS and table 8 results showed that POS significantly moderating role between OCB and OP. Previous research investigates the direct impact of POS in many outcomes, while few kinds of research have investigated the mechanisms of moderation through which POS impacts employees' attitudes and behaviors. One of the exceptions is Eisenberger et al.'s (2014).

\section{CONCLUSION AND RECOMMENDATIONS}

The targeted sample consisted of industrial employees. The survey research design and purposive sampling technique led to achieving the objectives of the current study. The present research confirmed a significant positive correlation between OCB, POS, and OP and moderating role of POS between Organizational Citizenship Behavior and organizational performance. The demographic variables significantly impact organizational citizenship behavior, perceived organizational support, and organizational performance.

There are practical implications of study findings for organizations, officials, and managers to further develop work attitudes and work behaviors and enhance their performance and productivity. Organizational citizenship behavior and POS are influential predictors of organizational performance. Both of these variables impact organizational processes and organizational outcomes. The interventions should embed and flourish certain organizational citizenship behaviors to enhance organizational performance.

\section{.LIMITATIONS AND STUDY FORWARD}

The prominent methodological limitation of this study is the research design and sample selection. Because of the crosssectional study and survey research method, the relationships between POS, OCB, and OP were explained as relational rather than causal relations. Further studies should also research the effects of other organizational factors on organizational performance through a longitudinal study. There is a need for research to study the mechanism and range of organizational variables through which organizational factors and processes influence employee behaviors.

\section{ACKNOWLEDGEMENT}

I am grateful to all people involved in conducting and improving the research quality of this paper.

\section{AUTHORS' CONTRIBUTION}

Andleeb Akhtar and Sadaf Ahsan worked on the drafting of the manuscript and have carried statistical analysis whereas Syeda Naila Andleeb, Saira Bano, and Rimsha Kainat performed interpretations and technical parts.

\section{REFERENCES}

1 Acaray, A., \& Akturan, A. (2015). The relationship between organizational citizenship behaviour and organizational silence. Procedia-Social and Behavioral Sciences, 207, 472-482.

2 Alexandru, C. (2012). The impact of supply chain performance on organizational performance. Journal of Electrical and Electronics Engineering, 1(2), 45-48.

3 Allen, D. G., \& Shanock, L. R. (2013). Perceived organizational support and embeddedness as key mechanisms connecting socialization tactics to commitment and turnover among new employees. Journal of Organizational Behavior, 34, 350-369. https://doi.org/10.1002/job.1805

4 Beauregard, T. A. (2012). Perfectionism, self-efficacy and OCB: The moderating role of gender. Personnel Review. 41, 590-608. https://doi.org/10.1108/00483481211249120

5 Chiang, C. F., \& Hsieh, T. S. (2012). The impacts of perceived organizational support and psychological empowerment on job performance: The mediating effects of organizational citizenship behavior. International Journal of Hospitality Management, 31(1), 180-190.

6 Choi, J. N. (2009). Collective dynamics of citizenship behavior: what group characteristics promote group-level helping? Journal of Management Studies, 46, 1396-1420. https://doi.org/10.1111/j.1467-6486.2009.00851.x

7 Cullen, K. L., Edwards, B. D., Casper, W. C., \& Gue, K. R. (2014). Employees' adaptability and perceptions of change-related uncertainty: Implications for perceived organizational support, job satisfaction and performance. Journal of Business and Psychology, 29, 269-280. https://doi.org/10.1007/s10869-013-9312-y

8 Datta, D. K., Guthrie, J. P., \& Wright, P. M. (2005). Human resource management and labor productivity: Does industry matter?. Academy of Management Journal, 48(1), 135-145.

9 DiRenzo, M. S., Greenhaus, J. H., \& Weer, C. H. (2011). Job level, demands, and resources as antecedents of work-family conflict. Journal of Vocational Behavior, 78(2), 305-314. Retrieved from https://www.sciencedirect.com/science/article/abs/pii/S0001879110001673?via\%3Dihub

10 Duffy, J. A, \& Lilly, J. (2013). Do individual needs moderate the relationships between organizational citizenship behavior, organizational trust and perceived organizational support? Journal of Behavioral \& Applied Management, 14, 185-197.

11 Eisenberger, R., Huntington, R., Hutchinson, S., \& Sowa, D. (1986). Perceived organizational support. Journal of Applied Psychology, 71, 500-507

12 Eisenberger, R., Huntington, R., Hutchison, S., \& Sowa, D. (1986). Does pay for performance increase or decrease perceived self-determination and intrinsic motivation? Journal of Personality and Social Psychology, 
77, 1026-1040.

13 Eisenberger, R., Shoss, M. K., Karagonlar, G., Gonzalez-Morales, M. G., Wickham, R. E., \& Buffardi, L. C. (2014). The supervisor POS-LMX-subordinate POS chain: Moderation by reciprocation wariness and supervisor's organizational embodiment. Journal of Organizational Behavior, 35, 635-656. https://doi.org/10.1002/job.1877

14 Gavino, M. C., Wayne, S. J., \& Erdogan, B. (2012). Discretionary and transactional human resource practices and employee outcomes: The role of perceived organizational support. Human Resource Management, 51(5), 665-686.

15 Germeys, L., Griep, Y., \& de-Gieter, S. (2019). Citizenship pressure as a predictor of daily enactment of autonomous and controlled organizational citizenship behavior: Differential spillover effects on the home domain. Frontiers in Psychology, 10, 395-400. https://doi.org/10.3389/fpsyg.2019.00395

16 Jain, A. K., Giga, S. I., \& Cooper, C. L. (2013). Perceived organizational support as a moderator in the relationship between organisational stressors and organizational citizenship behaviors. International Journal of Organizational Analysis, 21(3), 313- 334. https://doi.org/10.1108/IJOA-Mar-2012-0574

17 Jebeli, M. J., \& Etebarian, A. (2015). Perceived organizational support and organizational citizenship behavior. Journal of MAGNT Research Report, 3 (4), 153-158.

18 Kumar, M. M., \& Shah, S. A. (2015). Validation of the psychological capital construct on the white collar employees of the human service organizations. Indian Journal of Positive Psychology, 6(4), 344.

19 Kuo, T.H. (2011). How to improve organizational performance through learning and knowledge. International Journal of Manpower, 23(5/6), 581-603.

20 Kurtessis, J.N., Eisenberger, R., Ford, M. T., Buffardi, L. C., Stewart, K. A., \& Adis, C. S. (2017). Perceived organizational support: A meta-analytic evaluation of organizational support theory. Journal of Management, 43, 1854-1884. https://doi.org/10.1177/0149206315575554

21 Lam, C. F., Wan, W. H., \& Roussin, C. J. (2016). Going the extra mile and feeling energized: An enrichment perspective of organizational citizenship behaviors. Journal of Applied. Psychology, 101, 379-391. https://doi.org/10.1037/ap10000071

22 Muhammad, A. H. (2014). Perceived organizational support and organizational citizenship behavior: The case of Kuwait. International Journal of Business Administration, 5(3), 59-69.

23 Paillé, P. (2011). Stressful work, citizenship behaviour and intention to leave the organization in a high turnover environment: Examining the mediating role of job satisfaction. Journal of Management Research, 3(1), 1-14.

24 Park, R. (2018). The roles of OCB and automation in the relationship between job autonomy and organizational performance: a moderated mediation model. International Journal of Human Resource Management, 29, 11391156. https://doi.org/10.1080/09585192.2016.1180315

25 Podsakoff, N. P., Whiting, S. W., Podsakoff, P. M., \& Blume, B. D. (2009). Individual-and organizational-level consequences of organizational citizenship behaviors: A meta-analysis. Journal of Applied Psychology, 94(1), 122.

26 Reizer, A., and Hetsroni, A. (2015). Caregiving representations at work and the moderating role of job selfefficacy. Psychological Reports, 116, 60-73. https://doi.org/10.2466/01.PR0.116k12w2

27 Rhoades, L., \& Eisenberger, R. (2002). Perceived organizational support: A review of the literature. Journal of Applied Psychology, 87, 698-714.

28 Robbins, S.P. \& Judge, T.A. (2015). Organisational Behavior. 16th edition, Pearson, Boston

29 Shaw, J. D., Park, T. Y., \& Kim, E. (2013). A resource-based perspective on human capital losses, HRM investments and organization performance. Strategic Management Journal, 34, 572-589. https://doi.org/10.10 02/smj.2025

30 Sidra, S., Imran, B., \& Adnan, A. (2016). Moderating role of psychological capital between perceived organizational support and organizational citizenship behavior and its dimensions. International Journal of Research Studies in Psychology, 5(2), 41-50. https://doi.org/10.5861/ijrsp.2016.1375

31 Sikorska -Simmons, E. (2005). Predictors of organizational commitment among staff in assisted living. The Gerontologist, 45(2), 196-205.

32 Singh, A. K., \& Singh, S. (2013). Perceived organisational support and organisational citizenship behaviour: The mediating role of personality. Journal of the Indian Academy of Applied Psychology, 39(1), 117-125. https://doi.org/264235815s

33 Stamper, C. L., \& Dyne, L. V. (2001). Work status and organizational citizenship behavior: A field study of restaurant employees. Journal of Organizational Behavior: The International Journal of Industrial, Occupational and Organizational Psychology and Behavior, 22(5), 517-536.

34 Taris, T. W., \& Schreurs, P. J. (2009). Well-being and organizational performance: An organizational-level test of the happy-productive worker hypothesis. Work \& Stress, 23, 120-136. https://doi.org/10.108 0/02678370903072555

35 Yaakobi, E. \& Weisberg, J. (2020). Organizational citizenship behavior predicts quality, creativity and efficiency performance: The roles of occupational and collective efficacies. Frontiers in Psychology, 11. https://doi.org/10.3389/fpsyg.2020.00758 